\title{
Pterydophyta Epifit Kawasan Wisata Air Terjun Jumog Ngargoyoso Karanganyar Jawa Tengah
}

\author{
EFRI ROZIATY, PUTRI AGUSTINA, RIZKA NURFITRIANTI \\ Prodi Pendidikan Biologi FKIP Universitas Muhammadiyah Surakarta \\ *email: er375@ums.ac.id
}

Manuscript received 26 Maret 2016, Revision accepted 26 Juli 2016

\begin{abstract}
Pterydophyta epifit merupakan jenis tumbuhan paku- pakuan yang hidup menempel pada tumbuhan lain. Metode survei diaplikasikan pada penelitian ini untuk pemilihan/penentuan lokasi pengambilan sampel. Penelitian ini bertujuan untuk menganalisis jenis - jenis Pterydophyta epifit yang berlokasi di sekitar kawasan wisata Air Terjun Jumog Karanganyar. Metode yang diaplikasikan pada penelitian ini adalah purpossive sampling melalui penjelajahan lokasi. Penjelajahan dilakukan pada kawasan yang terwakili seluas sekita 0.1 ha. Pada titik tertentu dibuat plot yang berukuran $2 \mathrm{~m} \times 2 \mathrm{~m}$. Jenis tumbuhan paku epifit yang ditemukan di kawasan ini terdiri dari 7 famili dan 11 spesies. Famili Pteridaceae terdiri dari 2 spesies yaitu Pteris multifida dan P. tripartita, Famili Adiantaceae terdiri dari 1 spesies yaitu Adiantum sp., Famili Aspleniaceae terdiri dari 2 spesies yaitu Asplenium nidus dan A. tripartita, Famili Davaliaceae terdiri dari Davalia denticulata, Nephrolepis acutifolia dan N. auriculata.
\end{abstract}

Keywords: epifit, pterydophyta, air terjun Jumog

\section{LATAR BELAKANG}

Kawasan air terjun Jumog merupakan kawasan yang termasuk ke dalam kawasan dataran tinggi. Kawasan ini terletak di lereng Gunung Lawu sekitar 500 m di sebelah barat Candi sukuh Karanganyar Jawa Tengah, berlokasi di Desa Berjo Kecamatan Ngargoyoso dengan koordinat

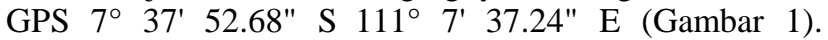
Sebagai salah satu kawasan dataran tinggi, di wilayah ini memiliki keanekaragaman floristik yang sangat tinggi. Tumbuhan epifit termasuk salah satu keanekaragaman hayati yang belum banyak diungkapkan sehingga pengetahuan tentang ini menjadi sangat sulit ditemui.

Epifit merupakan salah satu tumbuhan yang banyak terdapat di wilayah hutan tropis di Indonesia. Umumnya epifit terdapat di pohon - pohon di hutan. Tumbuhan epifit terdiri dari lumut - lumutan, paku - pakuan, dan anggrek - anggrekkan juga terna dan semak (Steenis, 2010). Tumbuhan epifit menempel pada tumbuhan sebagai karakteristik khasnya. Tumbuhan ini dapat menempel pada pohon - pohon atau bebatuan atau tanah di permukaan hutan yang lembab, sampah dedaunan dan dahan pohon yang telah tumbang, kotoran hewan yang telah berumur beberapa waktu. Tumbuhan epifit terdapat dalam jumlah yang melimpah (Setyawan, 2000) terutama di hutan - hutan tropik seperti di Indonesia dengan curah hujan dan kelembaban yang relatif tinggi. Tumbuhan ini melimpah pada tempat yang memiliki ketinggian sekitar 800 - $1000 \mathrm{dpl}$ (dataran tinggi) sehingga curah hujan tinggi, dekat dengan mata air berupa sungai dan atau air terjun. Epifit melakukan fotosintesis untuk pertumbuhannya sehingga epifit ini bukan termasuk organisme parasit. Epifit menjadi penting dalam ekosistem hutan karena menjadi tempat tumbuh bagi semut - semut pohon (Nawawi, Indriyanto, \& Duryat, 2014).
Vegetasi epifit yang termasuk ke dalam golongan tumbuhan paku (Pterydophyta) yang berukuran besar berasal dari genus Asplenium dengan daun - daun yang memanjang berukuran lebih dari $1 \mathrm{~m}$. Beberapa jenis tumbuhan epifit memanjat dengan akarnya yang melingkar sepanjang batang/dahan tumbuhan inang dan anggrek - anggrekan (Suwila, 2015).

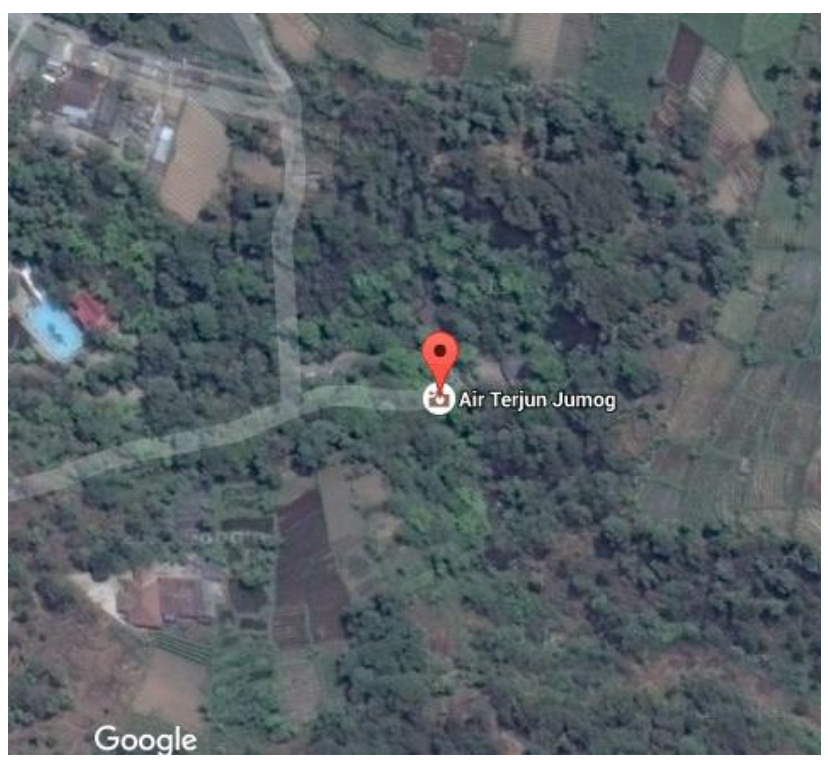

Gambar 1. Kawasan Wisata Air Terjun Jumog (Sumber : Google Maps)

Tumbuhan epifit golongan Pterydophyta menyukai tempat lembab dan basah sebagai tempat hidupnya di atas permukaan tanah (terestrial ataupun menempel pada pohon) lain. Tumbuhan paku memiliki keanekaragaman 
yang tinggi. Tumbuhan epifit golongan tumbuhan yang berbunga (Spermatophyta) (Tjitrosoepomo, 1992).

Menurut (Steenis, 2010), tidak terdapat suatu hubungan yang khusus antara tumbuhan epifit dengan pohon inangnya. Tumbuhan epifit jenis apa saja berkesempatan untuk bisa menetap pada pohon apa pun sepanjang tersedia humus bagi epifit. Hal ini terbukti pada jenis tumbuhan paku jenis apa saja. Sedangkan, untuk tumbuhan jenis lainnya selain Pterydophyta menunjukkan ada hubungan antara epifit dengan tumbuhan inangnya.

\section{TUJUAN}

Penelitian ini bertujuan untuk menganalisis jenis - jenis pterydophyta epifit di kawasan air terjun Jumog Desa Berjo Ngargoyoso Karanganyar Jawa Tengah.

\section{METODE}

\section{Lokasi dan waktu penelitian}

Penelitian ini dilakukan kawasan air terjun Jumog Desa Berjo Ngargoyoso Karanganyar Jawa Tengah. Penelitian dilaksanakan pada Bulan Juli sampai dengan Agustus 2016.

\section{Alat dan Objek Penelitian}

Alat yang digunakan dalam penelitian ini adalah alat tulis, tally sheet (lampiran 1), kamera, roll meter, gunting, tali plastik, counter, termohigrometer., dan soil tester. Objek dari penelitian ini adalah tumbuhan epifit jenis paku pakuan (Pteridophyta) .

\section{Jenis Data}

Data dari penelitian ini berupa: 1) data primer yaitu data yang didapat dari lapangan melalui pengamatan secara langsung. Data primer ini meliputi jenis dan jumlah tumbuhan pterydophyta epifit serta jenis tumbuhan penopang (inang); 2) data sekunder yaitu data yang bersifat mendukung data primer yaitu data karakteristik ekologi terkait faktor abiotik yaitu ketinggian, suhu, kelembaban, dan ph tanah di lokasi penelitian. Peta lokasi dari Google maps.

\section{Metode Penentuan Sampel}

Lokasi penelitian berada di kawasan air terjun Jumog Desa Berjo Kecamatan Ngargoyoso Karanganyar Jawa Tengah. Penelitian menggunakan petak contoh yang diistilahkan dengan plot. Plot yang diambil dengan terlebih dahulu melalui survei lokasi terlabih dahulu. Jarak antar plot masing - masing sekitar $10-20 \mathrm{~m}$. Metode ini digunakan karena dirasakan efektif dalam penelitian dengan kondisi topografi dan elevasi seperti kawasan air terjun Jumog. Metode ini digunakan untuk mengatasi medan yang memiliki kontur dan kemiringan, memotong sungai yang berasal dari air terjun. Data sekunder di dapatkan melalui kajian pustaka digunakan untuk mendukung data - data primer.

\section{Metode Pengumpulan data}

Penelitian menggunakan petak contoh dengan luas $2 \mathrm{~m}$ x 2 $\mathrm{m}$ sebanyak 11 plot contoh. Jika terdapat tumbuhan paku epifit pada plot diidentifikasi secara morfologis dan habitat. Faktor abiotik yang juga di amati adalah suhu, kelembaban, ketinggian dan tanah. Faktor abiotik tanah meliputi $\mathrm{pH}$ dan kelembaban tanah. Data - data dimasukkan ke dalam lembar pengamatan (tally sheet) yang telah disediakan. Identifikasi tumbuhan menggunakan buku Plants in Tropical Cities (Min, Chew, \& (John), 2014).

\section{HASIL DAN PEMBAHASAN}

\section{Hasil Penelitian}

Jenis tumbuhan paku epifit yang ditemukan di kawasan air terjun Jumog Ngargoyoso Karanganyar adalah 7 famili dan 11 spesies (Tabel 1). Famili Pteridaceae terdiri dari 2 spesies yaitu Pteris multifida dan P. tripartita, Famili Adiantaceae terdiri dari 1 spesies yaitu Adiantum sp., Famili Aspleniaceae terdiri dari 2 spesies yaitu Asplenium nidus dan A. tripartita, Famili Davaliaceae terdiri dari Davalia denticulata, Nephrolepis acutifolia dan $N$. auriculata.

Tabel 1. Tumbuhan epifit yang ditemukan pada batang pohon inang di kawasan air terjun Jumog Ngargoyoso Karanganyar

\begin{tabular}{|c|c|c|c|c|}
\hline No & Nama Ilmiah & Famili & $\begin{array}{c}\text { Inang/ } \\
\text { nama lokal }\end{array}$ & $\begin{array}{l}\text { Nama } \\
\text { ilmiah }\end{array}$ \\
\hline 1 & $\begin{array}{c}\text { Pteris } \\
\text { multifida }\end{array}$ & Pteridaceae & & \\
\hline 2 & P. tripartita & Pteridaceae & $\begin{array}{l}\text { Mahkota } \\
\text { dewa }\end{array}$ & $\begin{array}{c}\text { Phaleria } \\
\text { macrocarpa }\end{array}$ \\
\hline 3 & Adiantum sp. & Adiantaceae & Paku tiang & Cyatea sp. \\
\hline 4 & $\begin{array}{l}\text { Asplenium } \\
\text { nidus }\end{array}$ & Aspleniaceae & Palem & $\begin{array}{l}\text { Areca } \\
\text { catechu }\end{array}$ \\
\hline 5 & thunbergii & Aspleniaceae & Pinus & $\begin{array}{c}\text { Pinus } \\
\text { merkusii }\end{array}$ \\
\hline 6 & $\begin{array}{c}\text { Davalia } \\
\text { denticulata }\end{array}$ & Davaliaceae & Sengon & $\begin{array}{l}\text { Albizzia } \\
\text { chinensis }\end{array}$ \\
\hline 7 & $\begin{array}{l}\text { Nephrolepis } \\
\text { acutifolia }\end{array}$ & Davaliaceae & Jeruk & $\begin{array}{c}\text { Citrus } \\
\text { aurantium }\end{array}$ \\
\hline 8 & N. auriculata & Davaliaceae & $\begin{array}{c}\text { Palem } \\
\text { botol }\end{array}$ & $\begin{array}{l}\text { Hyophorbe } \\
\text { lagenicaulis }\end{array}$ \\
\hline 9 & $\begin{array}{l}\text { Ophioglossum } \\
\text { pendulum }\end{array}$ & $\begin{array}{l}\text { Ophioglossum } \\
\text { (5) }\end{array}$ & & \\
\hline 10 & $\begin{array}{l}\text { Microlepia } \\
\text { speluncae }\end{array}$ & $\begin{array}{c}\text { Dennstaedtiaceae } \\
\text { (6) }\end{array}$ & & \\
\hline 11 & Selaginella sp & $\begin{array}{c}\text { Selaginellaceae } \\
\text { (7) }\end{array}$ & & \\
\hline
\end{tabular}

Berdasarkan pengamatan di lokasi penelitian di dapatkan bahwa tumbuhan epifit menempel pada tumbuhan penopang yang memiliki bentuk tekstur kulit yang tebal, beralur maupun berserabut dan memiliki kulit yang keras (Tabel 1). Hal ini diduga merupakan faktor yang mempengaruhi tumbuhan epifit dengan tumbuhan penopang (inang) (Nawawi, Indriyanto, \& Duryat, 2014). Selain itu, ada kriteria lain yang dimiliki oleh tumbuhan penopang/inang yang disukai oleh paku epifit yaitu merupakan pohon yang memiliki usia tua dengan masa pertumbuhan dan perkembangan yang lebih dari satu tahun (perenial) (Suwila, 2015)

Kondisi iklim mikro yang telah diukur pada lokasi penelitian yaitu suhu lingkungan, kelembaban lingkungan, $\mathrm{pH}$ tanah dan kelembaban tanah (Tabel 2). 
Dari parameter tersebut dapat kita ketahui kondisi lingkungan abiotik yang dapat mengakomodasi kehidupan Pteridophyta di kawasan air terjun Jumog. Parameter abiotik berupa suhu lingkungan terlihat bahwa kondisi suhu lingkungan di laut berkisar antara $24,5^{\circ} \mathrm{C}-28,2^{\circ} \mathrm{C}$. Tumbuhan paku yang hidup pada daerah tropis umumnya dapat tumbuh pada suhu optimal $21-27^{\circ} \mathrm{C}$ untuk pertumbuhannya (Nawawi, Indriyanto, \& Duryat, 2014). Suhu yang rendah menyebabkan kelembaban tinggi hal ini disebabkan karena rendahnya intensitas cahaya (Sulistyowati, Perwati, \& Wiryani, 2014).

Tabel 2. Faktor abiotik pendukung pertumbuhan paku epifit

\begin{tabular}{ccc}
\hline No & Parameter & Kisaran \\
\hline 1 & Suhu Lingkungan & $24,8^{\circ} \mathrm{C}-30,6^{\circ} \mathrm{C}$ \\
2 & Kelembaban Lingkungan & $66 \%-82 \%$ \\
3 & pH tanah & $6.3^{\circ} \mathrm{C}-7{ }^{\circ} \mathrm{C}$ \\
4 & Kelembaban Tanah & $60 \%-90 \%$ \\
\hline
\end{tabular}

Dengan demikian suhu pada lokasi penelitian sangat cocok untuk pertumbuhan tumbuhan pteridophyta. Kelembaban lingkungan pada lokasi penelitian berkisar antara 64\% - 83\% termasuk dalam kategori lembab. Banyaknya jenis tumbuhan yang ada di kawasan air terjun Jumog Karanganyar membuktikan bahwa kawasan tersebut masih sangat alami serta masih terkategori seimbang. Ekosistem di wilayah tersebut masih relatif baik. (Supu \& Munir, 2009).

Faktor - faktor abiotik seperti suhu, kelembaban dan cahaya juga sangat berperan penting dalam proses pertumbuhan paku epifit di kawasan tersebut. Suhu yang rendah berkisar antara $24,8^{\circ} \mathrm{C}-30,6^{\circ} \mathrm{C}$ mempengaruhi pertumbuhan kanopi pohon. Kanopi pohon mempengaruhi kuantitasi oksigen dan karbodioksida di udara. Kanopi dapat mengurangi intensitas cahaya yang akan masuk sehingga suhu udara di dalam hutan menjadi semakin rendah. Hal ini menyebabkan udara di hutan terasa sejuk (Supu \& Munir, 2009).

$\mathrm{pH}$ tanah berkisar antara $4,9^{\circ} \mathrm{C}-6,8^{\circ} \mathrm{C}$ sedangkan kelembaban tanah mencapai $20 \%$ - 61\%. Dalam kondisi iklim tersebut sangat cocok sebagai habitat pertumbuhan pteridophyta. Kondisi ini menunjukkan bahwa tumbuhantumbuhana paku yang terdapat pada wilayah air terjun Jumog tergolong tumbuhan pegunungan bawah karena beradap pada ketinggian $980-1100 \mathrm{~m} / \mathrm{dpl}$.

\section{KESIMPULAN}

Jenis tumbuhan paku epifit yang ditemukan di kawasan air terjun Jumog Ngargoyoso Karanganyar adalah 7 famili dan 11 spesies. Famili Pteridaceae terdiri dari 2 spesies yaitu Pteris multifida dan P. tripartita, Famili Adiantaceae terdiri dari 1 spesies yaitu Adiantum sp., Famili Aspleniaceae terdiri dari 2 spesies yaitu Asplenium nidus dan A. tripartita, Famili Davaliaceae terdiri dari Davalia denticulata, Nephrolepis acutifolia dan N. auriculata.

\section{UCAPAN TERIMA KASIH}

Ucapan terima kasih penulis sampaikan kepada Lembaga Penelitian dan Pengabdian Masyarakat Universitas Muhammadiyah Surakarta.

\section{DAFTAR PUSTAKA}

Min, B. C., Chew, S. Y., \& (John), J. W. (2014). Plants in Tropical Cities. Singapore : Uvaria Tide.

Nawawi, G. R., Indriyanto, \& Duryat. (2014). Identifikasi Jenis Epifit dan Tumbuhan yang Menjadi Penopangnya di Blok Perlindungan dalam Kawasan Taman Hutan Raya Wan Abdul Rachman. Jurnal Sylva Lestari, 39-48.

Setyawan, A. D. (2000). Tumbuhan Epifit pada Tegakan Pohon Schima wallichii (D.C) Korth di Gunung Lawu. Biodiversitas, 14-20.

Steenis, C. v. (2010). Flora Pegunungan Jawa. Bogor, Indonesia: LIPI.

Sulistyowati, D. A., Perwati, L. K., \& Wiryani, E. (2014). Keanekaragaman Marchantiophyta Epifit Zona Montana di Kawasan Gunung Ungaran, Jawa Tengah. Bioma, 26-32.

Supu, H., \& Munir, A. (2009). Jenis - jenis Tumbuhan Epifit di Hutan Kawasan Sekitar Danau Lawulamoni Kecamatan Kabawo Kabupaten Muna. Warta Wiptek, 101-106.

Suwila, M. T. (2015). Identifikasi Tumbuhan Epifit Berdasarkan Ciri Morfologi dan Anatomi Batang di Hutan Perhutani Sub BKPH Kedunggalar Sonde dan Natah. Jurnal Florea, 47-50.

Tjitrosoepomo, G. (1992). Taksonomi Tumbuhan Schizophyta, Bryophyta, Thallophyta dan Pterydophyta. Jogjakarta: UGM Press. 